$$
\begin{array}{r}
\text { Pontifícia Universidade C Católica } \\
\text { do Rio de Janeiro }
\end{array}
$$

Ione Manzali de Sá

\title{
"Da verdade como abertura existencial ao acontecimento poético da verdade"
}

\author{
Dissertação de Mestrado
}

Dissertação apresentada ao Programa de Pós-graduação do Departamento de Filosofia da PUC-Rio como parte dos requisitos para a obtenção do grau de Mestre em Filosofia.

Orientador: Prof. Paulo Cesar Duque Estrada

Rio de Janeiro, 17 de agosto de 2010 


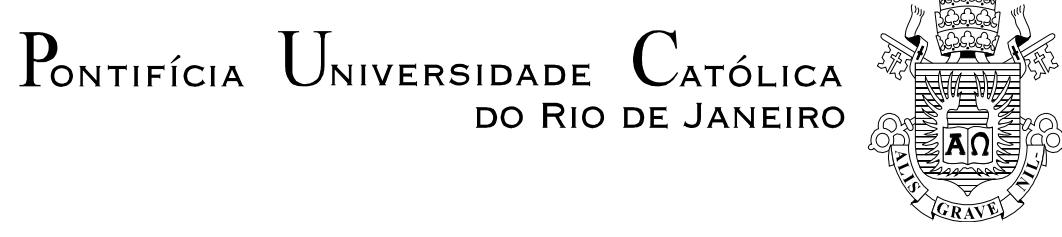

Ione Manzali de Sá

\title{
"Da verdade como abertura existencial ao acontecimento poético da verdade"
}

\begin{abstract}
Dissertação apresentada como requisito parcial para obtenção do grau de Mestre pelo Programa de Pós-Graduação em Filosofia do Departamento de Filosofia do Centro de Teologia e Ciências Humanas da PUC-Rio. Aprovada pela Comissão Examinadora abaixo assinada.
\end{abstract}

\author{
Prof. Paulo Cesar Duque Estrada \\ Orientador \\ Departamento de Filosofia - PUC-Rio
}

Profa. Ligia Teresa Saramago Pádua

Departamento de Filosofia - PUC-Rio

Prof. Marco Antonio dos Santos Casa Nova Universidade Estadual do Rio de Janeiro - UERJ

Prof. Paulo Fernando Carneiro de Andrade

Coordenador Setorial do Centro de Teologia

e Ciencias Humanas - PUC-Rio 
Todos os direitos reservados. É proibida a reproducão total ou parcial do trabalho sem autorização da universidade, da autora e do orientador.

\section{Ione Manzali de Sá}

Graduou-se em Arquitetura pela Universidade Santa Úrsula em 1986. Cursou a EAV do P. Laje de 1980 à 1986; desenvolveu projetos de arquitetura de 1986 à 1990; estudou pintura com R. Pousette-Dart na Art Student's League of New York em 1991; é responsável pela criação e educação de três seres humanos desde 1993; estudou na Baum School of Art de 1995 à 1998 e cinema na New York Film Academy em 2003. Participou de exposições de artes plásticas e de fotografia e na produção de vídeos artísticos no Brasil e nos Estados Unidos, assim como de colóquios e seminários abordando temas ligados à fenomenologia e a filosofia de Martin Heidegger.

\section{Ficha Catalográfica}

Manzali de Sá, Ione

Da verdade como abertura existencial ao acontecimento poético da verdade / Ione Manzali de Sá ; orientador: Paulo Cesar Duque Estrada. - 2010.

$141 \mathrm{f} . ; 30 \mathrm{~cm}$

Dissertação (Mestrado) - Pontifícia Universidade Católica do Rio de Janeiro, Departamento de Filosofia, 2010.

Inclui bibliografia

1. Filosofia - Teses. 2. Heidegger, Martin, 1889-1976. 3. Estética. 4. Verdade. 5. Arte. 6. Pós-modernismo. I. DuqueEstrada, Paulo Cesar. II. Pontifícia Universidade Católica do Rio de Janeiro. Departamento de Filosofia. III. Título.

CDD: 100 
Para minhas três obras de arte essenciais, Maïra, Théo e Ottavio 


\section{Agradecimentos}

À CAPES E PUC-Rio, pela oportunidade desta pesquisa se realizar.

Ao meu orientador, professor Paulo César Duque Estrada, pela confiança e orientação.

Ao professor Marco Antonio Casanova, pela sua dedicação ao legado heideggeriano.

À professora Ligia Saramago, pela participação na banca.

Ao professor Antônio Mattoso, pela introdução à escrita grega.

Aos professores do curso de especialização em Filosofia contemporânea e da pós graduação, Danilo Marcondes, Eduardo Jardim, Luis Camillo Osório, Edgar Lyra, Rafael Haddock-Lobo, Bárbara Botter, Vera Bueno, Kátia Muricy, Leandro Chevitarese, Rosana Suarez, Andreia Bieri e Marcus Reis.

Aos amigos e familiares e em particular à Ivone M. de Sá, pela companhia fraterna e pelo diálogo intelectual.

À Geraldo e Wanda, pelo apoio de toda vida.

À memória de Hilda de Souza Manzali. 


\section{Resumo}

Manzali de Sá, Ione; Duque Estrada, Paulo César (Orientador). Da verdade como abertura existencial ao acontecimento poético da verdade. Rio de Janeiro, 2010. 141p. Dissertação de Mestrado Departamento de Filosofia, Pontifícia Universidade Católica do Rio de Janeiro.

Na sua conferência A origem da obra de Arte, de 1936, Martin Heidegger leva a discussão sobre a arte, até então restrita ao domínio da estética, para o campo ontológico, na sua definição da obra de arte como o "pôr-se-em-obra da verdade”. Nesta dissertação intento esclarecer esta peculiar expressão, tomando como fio condutor as mudanças do sentido de verdade que acompanharam o motivo central na filosofia de Heidegger, a questão do ser, desde Ser e tempo até o seu encontro com a arte nesta conferência. Heidegger, em seu empenho contra a entranhada tradição da verdade como verdade eterna, noção esta que mostrou ser comandada pela lógica da adequação, parte da noção de verdade histórica por ele definida nos anos 1930, para chegar ao mais original sentido da verdade de ocultamento e desvelamento da alétheia, que, ao se essencializar, "acontece" poeticamente na obra de arte, instaurando a verdade de um novo ser ao abrir horizontes históricos-destinais. Mostrarei por fim, como a techné, neste momento compreendida por Heidegger como original [ursprünglich], é por ele então pensada na abertura instaurada pela obra de arte associadamente à essencialização da técnica moderna em seu desabrigar dos entes como recurso disponível de uma vigência estabilizada.

\section{Palavras-chave}

Heidegger; estética; verdade; arte; pós-modernismo 


\section{Abstract}

Manzali de Sá, Ione; Duque Estrada, Paulo César (Advisor). From truth as existencial disclosure to the poetic happening of truth. Rio de Janeiro, 2010. 141p. MSc. Master Program Thesis - Departament of Philosophy, Pontifícia Universidade Católica do Rio de Janeiro.

In his conference The Origin of the Work of Art, of 1936, Martin Heidegger takes the discussion about art, then restricted to the domain of the aesthetics, to the ontological field, when defining the work of art as the settingitself-to-work of the truth. In this dissertation I aim to clarify this peculiar expression, taking as a thread changes in the meaning of truth that followed the central motif in the philosophy of Heidegger, the question of being, since Being and Time until his encounter with art in this conference. Heidegger, in his persistence against the ingrained tradition of truth as perpetual truth, notion pointed by him as being commanded by a logic of adequacy, takes the notion of historical truth defined by him in the1930s, to find the most original truth of veiling and disclosure of the alétheia, that in its essencialization "happens" poetically as a work of art, establishing the truth of a new being in its opening of historical-destinals horizons. At last, I will show how Techné, understood by Heidegger then as original [Ursprünglich], is presented by him as the clearing of an open by the work of art in association with the essentialization of modern technique in its unshelter of beings as available resource of a stabilized sway.

\section{Keywords}

Heidegger; aesthetics; truth; art; post-modernism 


\section{Sumário}

Introdução

1. Verdade e techné artesanal

1.1. A verdade lógica, fenomenológica e hermenêutica

1.2. A verdade transcendental e existencial de Ser e Tempo

1.3. A essência da verdade: $§ 44$ de Ser e Tempo

2. Die Kehre, a viragem de Heidegger

2.1. A viragem de 1930: verdade histórica e verdade do ser

2.2. Os textos da Kehre: historicidade, negatividade, lógica e linguagem

2.3. O acontecimento-apropriador [Ereignis]

3. O pôr-se em obra da verdade em $A$ origem da obra de arte

3.1. A concepção estética da obra de arte

3.2. A coisa e a obra

3.3. A obra e a verdade

3.4. A verdade e a arte

3.5. Mundo e Terra

3.6. Arte e historicidade

3.7. Arte, linguagem e poesia

4. Verdade e techné industrial

4.1. Modernidade tardia e niilismo

4.2. A doutrina platônica da verdade

4.3. O fim da metafísica e A questão da técnica

5. Considerações finais

6. Referências bibliográficas 


\section{Observações}

1) O termo Dasein foi utilizado tal como no original alemão. Este termo aparece em todas as citações do original alemão, a fim de evitar o conflito das diferentes traduções para o português, sendo as mais comuns ser-aí, pre-sença, situação humana e existência humana. Pela mesma razão, adotei em todas as citações o termo utensílio para a palavra Zeug conforme as indicações do prof. Casanova. Favoreci ainda ek-sistência sobre existência para marcar o sentido particular de movimento ekstático que Heidegger assinala nesta palavra.

2) Tendo em vista a dificuldade de tradução da riqueza etimológica e do jogo sonoro da prosa da filosofia heideggeriana, coloco em parêntesis [ ] os termos originais utilizados por Heidegger, tanto grego tanto alemão, sempre que possível. Os parêntesis quando utilizados por Heidegger estão na forma ( ) e as minhas observações foram colocadas na forma \{\} .

3) Utilizei como referência principal ao texto de A Origem da Obra de arte, a tradução de Maria da Conceição Costa, e como referência suplementar a edição norte-americana publicada na coletânea Holzwege além da dissertação de mestrado A Origem da obra de arte de Martin Heidegger. Tradução, Comentário e Notas de Laura de Borba Moosburger. Salvo indicado, as citações de A Origem da Obra de arte foram extraídas da edição portuguesa, ocorrendo ocasionalmente a substituição de termos heideggerianos pelos de outros de tradutores. 